\title{
Correction to: Evaluation of Mechanical and Microstructure Properties of Mg-Modified Aluminum Matrix Composite by Vortical Casting Method
}

\author{
Saeed Pashmforoosh ${ }^{1} \cdot$ Sadegh Shahriyari $^{1} \cdot$ Omid Mirzaee $^{2}$
}

Published online: 11 July 2020

(c) The Korean Institute of Metals and Materials 2020

\section{Correction to: Metals and Materials International https://doi.org/10.1007/s12540-020-00639-3}

In the original publication of the article the third author's affiliation was published incorrectly. The correct affiliation is given in this correction.
Publisher's Note Springer Nature remains neutral with regard to jurisdictional claims in published maps and institutional affiliations.

The original article can be found online at https://doi.org/10.1007/ s12540-020-00639-3.

Sadegh Shahriyari

s.shahriyari89@gmail.com

1 Department of Materials Engineering, Ahvaz Branch, Islamic Azad University, Ahvaz 6134937333, Iran

2 Faculty of Materials and Metallurgical Engineering, Semnan University, Semnan 19111-35131, Iran 